\title{
Injecting drug users, MSM and people at the older age should be routinely tested for HCV in Poland - data derived from a post-exposure prophylaxis population
}

\author{
Karolina Agnieszka Pyziak-Kowalska ${ }^{1, A-D, F \oplus}$, Maksymilian Bielecki ${ }^{2, C \oplus}$, Andrzej Horban ${ }^{1, E-F \oplus,}$ \\ Justyna Kowalska ${ }^{1, A, C, E-F \oplus ~}$ \\ ${ }^{1}$ Medical University, Warsaw, Poland \\ 2 SWPS University of Sciences and Humanities, Warsaw, Poland \\ A - Research concept and design, B - Collection and/or assembly of data, C - Data analysis and interpretation, \\ $D$ - Writing the article, E - Critical revision of the article, F - Final approval of article
}

Pyziak-Kowalska KA, Bielecki M, Horban A, Kowalska J. Injecting drug users, MSM and people at the older age should be routinely tested for HCV in Poland - data derived from the post-exposure prophylaxis population. Ann Agric Environ Med. 2021 ; $633-638$. doi: 10.26444/aaem/131119

\begin{abstract}
Objective. The aim of the study was to identify risk factors for HCV infection and thus identify groups for routine HCV testing in the group of people consulted for post-exposure prophylaxis (PEP).

Materials and method. A retrospective analysis was performed of cross-sectional data available from consultations due to post-exposure prophylaxis in HIV Out-patient Clinic and Emergency Department (ED) of Hospital for Infectious Diseases in Warsaw, Poland. Data were obtained from the electronic database, from 2008-o 2016. For statistical analysis, X2 and t-tests were used for group comparisons, as appropriate. A total of 3,593 persons were included in the study, 60 (1.7\%) were antiHCV positive. In the first step, univariate models were estimated for each of predictors separately.

Results. The results showed that odds of infection are significantly higher in males $(\mathrm{OR}=1.92)$, people after non-professional exposure $(O R=3.82)$, and increase with age $(O R=1.03)$. In the next step, a multivariate logistic model was fitted in the group of participants after non-professional exposure with gender, age, and route of exposure as predictors. Obtained results revealed significantly higher odds of infection, both in IDU $(O R=162.6)$ and gender exposure $(O R=3.59)$ groups. After including routes of exposure, effects of age remained significant $(O R=1.05)$, while the effects of gender did not $(O R=1.12)$. Conclusions. Based on the study results, it is recommended that routine testing for HCV should be provided for people at older age, and for individual with behavioural risk factors, such as history of injecting drus use or sexual exposure, particularly among men having sex with men (MSM).
\end{abstract}

\section{Key words}

professional exposure, pos-exposure prophylaxis, risk factors for HCV infection, HCV testing, non-professional exposure

\section{INTRODUCTION}

According to the data provided by the World Health Organization (WHO) in 2017, up to 71 million people worldwide and 3.9 million in Europe were chronically infected with HCV $[1,2]$. Despite this, the testing rates for hepatitis $C$ are still relatively low due to the lack of possible general screening in the risk groups. Finding a solution to this problem constitutes one of the most relevant challenges as it will allow overcoming the difficulties and potential for the missed opportunities for the HCV and HIV testing [1, $3-5]$. Moreover, this could prevent late presentation as the majority of people who are chronically HCV infected, are asymptomatic until the late stage of the liver disease [6]. Furthermore, many individuals are unaware of their status due to insufficient awareness or lack of knowledge regarding the potential sources or risks of infection, which constitute the leading and most frequent causes of the low rates of the HCV and HIV detection in the general population $[7,8]$.

Address for correspondence: Karolina Agnieszka Pyziak-Kowalska, Medical University, Żwirki i Wigury 61, 02-091 Warsaw, Poland

E-mail: karolina.pyziak@gmail.com

Received: 27.04.2020; accepted: 30.11.2020; first published: 15.12.2020
Poland belongs to the countries with low seroprevalence of $\mathrm{HCV}$ infection, thus the entire 'population-based screening strategy' is not recommended as it is not cost-effective. It is said that the strategies aimed at preventing new infections should be 'tailored to address the most common modes of transmissions' $[7,9,10]$. In Poland, more than 1,400 new cases of HIV and more than 3,500 of HCV were diagnosed in 2018 [11, 12]. Current statistics indicate that one in five persons infected with HCV are aware of their status [11, 13].

Similar to international data, in Poland the risk groups are quite well understood and include: people who inject drugs (PWID), migrants, people in prison, transfusion recipients prior to universal donation screening before 1992, HIV positive men who have sex with men, and patients who have been hospitalized more than three times in their lives [14-19].

The lack of possibility to find an appropriate testing strategy to reach the risk groups is still problematic and constitutes one of the most relevant issues in the area of public health in Poland [20]. Unfortunately, the major problem is still the lack of a national screening programme for HCV infection in Poland. The remaining patients are an anonymous reservoir of the virus, which influences the dynamics of the epidemic of the viral hepatitis $[21,22]$. Research in this area is scarce. 
Many projects involving routine screening failed to identify new infections and guide behavior-based testing, because no appropriate regulations have been made at government level [23].

\section{OBJECTIVE}

The aim of the study was to identify the risk factors for HCV infection, and thus identify groups for routine HCV testing in people consulted for post-exposure prophylaxis (PEP) -patients attending the Out-Patient Clinic of the Hospital for Infectious Diseases in Warsaw.

\section{MATERIALS A ND METHOD}

A retrospective analyses was performed of data available from consultations due to post-exposure prophylaxis in the HIV Out-patient Clinic and Emergency Department (ED) of the Hospital for Infectious Diseases in Warsaw. The data presented and analysed in this study were obtained from an electronic database prospectively designed to collect all medical information for PEP patients since 2008. A manual review of medical charts was carried out in the case of ambiguous data. The data analyzed included information about type of exposure, age, gender, exposure source (if available), and only baseline laboratory tests. Type of exposure was categorized as occupational and non-occupational exposure. The Hospital for Infectious Diseases provides post-exposure prophylaxis according to Polish AIDS Society Recommendations [24]. Blood samples for baseline serology are taken according to post-exposure prophylaxis procedures.

At baseline visit, serological tests were performed for all patients (anti-HCV test, HBsAg and HIV DUO test). It should be noted that risk contacts included occupational exposure, defined as exposure to potentially infectious material as a result of a needle-stick injury or other devices contaminated with blood that occur during work (e.g. medical doctors, dentists, nurses, laboratory staff, cleaning staff, firemen, policemen, city guards and prison staff). The so-called nonoccupational exposure refers to exposure to a particular infectious factor - 'an infectious agent' which occurs outside the professional environment (e.g. during sex; when sharing needles used to inject drugs, or after incidental contact with a needle or other devices contaminated with blood). Routes of exposure were defined in five categories: contact with blood, contact with other infectious material, needle injury, sexual contact (heterosexual or men having sex with men), as well as intravenous drug use (IDU).

For statistical analysis, $\chi 2$ and t-tests were used for group comparisons, as appropriate. Positivity rates of tests were reported with $95 \%$ confidence intervals. Analyses concerning types of exposure were performed using univariate and multivariate logistic regressions with profile-likelihood. In each analysis, the category with the lowest infection rate was selected as reference. Logistic regression models were used in order to identify factors associated with a positive anti-HCV test (all with $\mathrm{p}<0.1$ in univariate included in the final model). Due to the low positivity rate, the HIV test status was not included in the presented model. All p-values were calculated using two-sided tests. All computations were performed with the use of the R version 3.4.2 (R Core team, 2017)

\section{RESULTS}

The initial database included 5,195 patients aged 18-80 years at the time of visit (routine check-ups of medical stuff were not included into this database) from 7 January 2008 - 17 May 2016. All the cases with unknown route of exposure (1,594 cases, $30.7 \%$ of the sample) and eight cases with inconclusive $\mathrm{HCV}$-antibody test results $(0.2 \%$ of the sample) were excluded. Patient data concerning the results of serological tests performed during the first visit were finally included in the analysis.

A total of 3,593 persons were included in the study, 60 (1.7\%) were anti-HCV positive, thirty four (1.0\%) HBsAg positive, and four (0.1\%) anti-HIV/p24 positive. Among them, two persons were both anti-HCV and HBsAg positive, one both anti-HIV/p24 and HCV positive.

Comparison of basic demographic characteristics indicated that the anti-HCV positive group included fewer females (41.7 vs $57.8 \%$ ) and were older (40.0 vs 35.7 years of age) when compared with anti-HCV negative group. The proportion of occupational exposures in the $\mathrm{HCV}+$ group was markedly lower than in the HCV- sample (31.7 vs 63.9\%) (Tab. 1).

Table 1. Comparison of demographic characteristics of HCV- and HCV+ groups [1]

\begin{tabular}{lcccc}
\hline & $\begin{array}{c}\text { Total } \\
(\mathrm{N}=3593)\end{array}$ & $\begin{array}{c}\mathrm{HCV}- \\
(\mathrm{N}=3533)\end{array}$ & $\begin{array}{c}\mathrm{HCV}+ \\
(\mathrm{N}=60)\end{array}$ & P value \\
\hline Gender N (\% of females) & $2,066(57.5)$ & $2,041(57.8)$ & $25(41.7)$ & $\mathbf{0 . 0 1 8}$ \\
\hline Age in years (M +/- SD) & $35.72(11.6)$ & $35.7(11.5)$ & $40.0(12.9)$ & $\mathbf{0 . 0 1 3}$ \\
\hline $\begin{array}{l}\text { Professional exposures } \\
\mathrm{N}(\%)\end{array}$ & $2277(63.4 \%)$ & $2258(63.9 \%)$ & $19(31.7 \%)$ & $<\mathbf{0 . 0 0 1}$ \\
\hline
\end{tabular}

Distribution of exposure routes across HCV negative and HCV positive groups are shown in Table 2.

Table 2. Distribution of exposure routes across HCV- and HCV+ groups

\begin{tabular}{lcccc}
\hline $\begin{array}{l}\text { Route of } \\
\text { exposure: }\end{array}$ & $\mathrm{N}(\%)$ & $\begin{array}{c}\mathrm{N} \text { (\% within } \\
\text { group) } \\
\mathrm{HCV}-\end{array}$ & $\begin{array}{c}\mathrm{N} \text { (\% within } \\
\text { group) } \\
\mathrm{HCV}+\end{array}$ & $\begin{array}{c}\text { Infection Rate } \\
(95 \% \mathrm{Cl})\end{array}$ \\
\hline $\begin{array}{l}\text { Contact with } \\
\text { infectious material }\end{array}$ & $235(6.5 \%)$ & $233(6.6 \%)$ & $2(3.3 \%)$ & $\begin{array}{c}0.85 \% \\
(0.15-3.37 \%)\end{array}$ \\
\hline IDU & $28(0.8 \%)$ & $14(0.4 \%)$ & $14(23.3 \%)$ & $\begin{array}{c}50.0 \% \\
(32.6-67.4 \%)\end{array}$ \\
\hline Needle & $2027(56.4 \%)$ & $2007(65.8 \%)$ & $20(33.3 \%)$ & $\begin{array}{c}0.99 \% \\
(0.62-1.54 \%)\end{array}$ \\
\hline Blood & $590(16.4 \%)$ & $584(16.5 \%)$ & $6(10.0 \%)$ & $\begin{array}{c}1.02 \% \\
(0.41-2.32 \%)\end{array}$ \\
\hline Sex & $713(19.8 \%)$ & $695(19.7 \%)$ & $18(30.0 \%)$ & $\begin{array}{c}2.52 \% \\
(1.55-4.04 \%)\end{array}$ \\
\hline
\end{tabular}

Logistic regression models. The predictors associated with anti-HCV positive test were investigated by fitting a series of logistic regression models. In the first step, univariate models were estimated for each of the predictors separately in the whole sample (Tab. 3). The results showed that odds of infection were significantly higher in males, people after non-professional exposure, and increase with age. Analysis including routes of transmission revealed significant change in odds when IDU group was compared to the reference category, i.e. patients who had contact with infected material. 
Table 3. Univariate logistic regressions models predicting positive results of anti-HCV positive test

\begin{tabular}{lcccc}
\hline & \multicolumn{5}{c}{$95 \%$ profile-likelihood Cl } \\
\hline Route of exposure: & OR & LL & UL & p \\
\hline Infectious material & - & - & - & - \\
\hline IDU & 116.50 & 29.03 & 791.16 & $<0.001$ \\
\hline Needle & 1.16 & 0.34 & 7.30 & 0.838 \\
\hline Blood & 1.20 & 0.27 & 8.21 & 0.824 \\
\hline Sex & 3.03 & 0.86 & 19.07 & 0.089 \\
\hline Sex (male) & 1.92 & 1.15 & 3.25 & 0.013 \\
\hline Age (in years) & 1.03 & 1.01 & 1.05 & 0.006 \\
\hline $\begin{array}{l}\text { Type of exposure } \\
\text { (non-professional) }\end{array}$ & 3.82 & 2.24 & 7.76 & $<0.001$ \\
\hline
\end{tabular}

OR - odds ratios, LL - lower limit, UL - upper limit

In the next step, a multivariate logistic regression model was fitted in the group of participants after non-occupational exposure with gender, age, and route of exposure as predictors. That allowed retention in the model of all routes of exposure (sex and IDU routes were not present in the professional group) while controlling for the demographic variables.

Obtained results revealed a significantly higher odds of infection both in IDU and gender exposure groups. After including the routes of exposure, the effects of age remained significant, while the effects of gender did not (Tab. 4.)

Table 4. Multivariate logistic regressions model - non-occupational exposures group

\begin{tabular}{lcccc}
\hline \multicolumn{5}{c}{ 95\% profile-likelihood Cl } \\
\hline OR & LL & UL & $\mathrm{p}$ \\
\hline Route of exposure: & & & & \\
\hline Infectious material & 1 & & 1139.85 & $<.001$ \\
\hline IDU & 162.60 & 38.55 & 6.83 & 0.925 \\
\hline Needle & 1.07 & 0.30 & 9.24 & 0.717 \\
\hline Blood & 1.34 & 0.30 & 22.87 & 0.048 \\
\hline Sex & 3.59 & 1.01 & 2.07 & 0.727 \\
\hline Sex (male) & 1.12 & 0.60 & 1.07 & $<.001$ \\
\hline Age (in years) & 1.05 & 1.03 & &
\end{tabular}

The multivariate analysis including exposure (Tab. 5.) showed a similar pattern, confirming that non-professional exposure was related to higher infection odds, as was participant's age, whereas the effects of gender were no longer significant.

Table 5. Multivariate logistic regressions model

\begin{tabular}{lcccc}
\hline & \multicolumn{5}{c}{$95 \%$ profile-likelihood Cl } \\
\hline & OR & LL & UL & $p$ \\
\hline $\begin{array}{l}\text { Exposure } \\
\text { (Non-occupational) }\end{array}$ & 3.67 & 2.10 & 6.23 & $<.001$ \\
\hline Sex (male) & 1.53 & 0.89 & 2.67 & 0.127 \\
\hline Age (in years) & 1.04 & 1.02 & 1.06 & $<.001$ \\
\hline
\end{tabular}

1. Nijmeijer BM, Koopsen J, Schinkel J, Prins M, Geijtenbeek TB. Sexually transmitted hepatitis C virus infections: current trends, and recent advances in understanding the spread in men who have sex with men. Journal of the International AIDS Society. 2019;22(S6):e25348.
In the final multivariate analysis, occupational and nonoccupational exposures were included, together with gender, age and exposure route as predictors (limiting the sample to the routes present in both groups, ie. needle, blood, and infectious material). In this model, only age was significantly related to the risk of infection; therefore, detailed results are not reported for the sake of brevity. It is important to underline, that after excluding the IDU and sexual exposure, the overall number of HCV infections was 26 , severely limiting the power of that analysis.

\section{DISCUSSION}

The study presents high rates of anti-HCV positive test results among persons consulted for post-exposure prophylaxis, $1.7 \%$ compared to the general population rate of $1.0 \%$ in Poland. While the rate of the positive anti-HCV tests was higher among non-occupational exposures (3.11\%), it was slightly lower among occupational exposures $(0.83 \%)$ when compared with the rate observed in the general Polish population [13].

According to a recent systemic review from 2017 in the EU/ EEA countries, the prevalence of anti-HCV in the general population of individual Member States is estimated to vary from $0.1 \%-5.9 \%$ [25]. Compared to Polish data, countries in Eastern and South-Eastern Europe have higher prevalence estimates. On the other hand, people who were consulted for the post-exposure prophylaxis might be at higher risk for $\mathrm{HBV}, \mathrm{HCV}$ or HIV infection due to the earlier exposures for blood-borne viruses.

In addition, the current our study, based on a large population of persons consulted for post-exposure prophylaxis, shows several significant risk factors of $\mathrm{HCV}$ infection. First of all, the reported data indicated that positive $\mathrm{HCV}$ test was associated with injecting drugs. These data are consistent with the findings of a recent systemic review of hepatitis $\mathrm{C}$ sero-prevalence in the EU/EEA countries, which indicated that the most commonly reported route of transmissions among all disease categories was injecting drugs (55\% among chronic and $40 \%$ among acute cases) [26]. Therefore, it is unquestionable that currently sharing of needles and other equipment in the process of injecting drugs remains the most relevant factor for $\mathrm{HCV}$ transmission in developed countries [27]. In Poland, people who inject drugs (PWID) are one of the important groups at risk for $\mathrm{HCV}$ infection, with geographical variation in particular regions (univariable and adjusted ORs with respect to the region with the lowest prevalence varied up to 2.8 and 3.8 for $\mathrm{HCV}$ infection, respectively). Data point to the need for a stronger investment in preventive measures [28]. In addition, recent research indicates the quick need for changes in harm reduction programmes in Poland. Besides, it is worth emphasizing that drug users, especially those who inject drugs, are one of the most vulnerable groups in the population, because in countries with a high standard of medical care, people who inject drugs are the main group determining the dynamics of HCV epidemics [29, 30].

Additionally, the presented analysis showed association between positive HCV test result and sexual exposures, as well as older age. Reported data also indicated that hepatitis C infection predominantly affects men between $35-44$ years. The results of the current study showed similarly that odds 
of infection were almost twice as high for men and 160 times higher for injecting drugs.

The presented analysis of the PEP population shows that the odds of infection are almost four times higher among male participants $(\mathrm{OR}=3.59$, CI 1.01-22.87), but after including the routes of exposure, the effects of gender were no longer significant $(\mathrm{OR}=1.12, \mathrm{CI} 0.60-2.07)$. The $\mathrm{HCV}$ was pre-selected as a result of the characteristics of patients who reported (patients after sexual exposure with HCV infected partners). It is worth emphasizing that many studies have shown that heterosexual intercourse plays a relatively insignificant role in transmission of hepatitis C [31]. A majority of the said studies indicated that the risk factors responsible for transmission included vaginal mucosal damage, genital erosive lesions, traumatic sexual intercourse with abrasion of the genital mucosa, via reuse of razors, medical devices and manicure devices contaminated with blood [32-34]. Transmission occurs very rarely through vaginal intercourse compared to anal intercourse (particularly among men who have sex with men - the group also referred to as 'MSM'), when HCV infection happen several times more frequently [35].

According to the findings presented in the ECDC report, the prevalence of anti-HCV antibodies in the men having sex with men group had a higher than expected prevalence in the general population across the European Economic Area Countries (highest prevalence - 4.7\%)[2]. The higher possibility of infections occurring during anal intercourse may be connected with co-infection with HIV or other sexually transmitted diseases with disruption of mucosal tissue [36]. Therefore it is viable to screen for HCV all persons diagnosed with sexually transmitted disease [37]. Recent studies strongly suggest that the epidemic of sexually transmitted HCV infections in MSM Has continued to spread during recent decade[38, 39]. It is worth emphasising that targeted and preventive measures are essential to stop the transmission of $\mathrm{HCV}$, including increased testing to prevent the transmission of HCV in the MSM community [40].

Although associations with sexual exposures were noted, and the spread in this population was demonstrated, the nature of these and the burden of HCV among MSM remains unclear[41, 42]. Due to the limitations of the available data, it was not reliably possible to separate MSM vs MSW exposures for direct comparison in the presented sample. However, based on incomplete declarative responses, it was possible to confirm that at least 193 out of 451 (42.8\%) non-occupational sexual exposures in males were MSM contacts. To the best of the authors' knowledge, the results they obtained are the first to present in Polish population that sexual exposure in MSM poses a risk of HCV infection. The study also identified that people with older age are at greater risk for HCV. Similar results have been shown in several different studies, e.g. in the United States, Canada and Argentina. According to a study conducted in the USA, everyone who was born between 1945 - 1965 should undergo testing for HCV infection without prior ascertainment of HCV risk; similarly, in Canada persons born between 1945 - 1975, and in Argentina persons born before 1973 [43-45]. Similarly, in other studies conducted in Poland, the highest percentage of $\mathrm{HCV}$ antibodies occurred in the population aged over $50(2.93 \%)$ [46, 47]. The increased prevalence of anti-HCV is probably associated with several factors, including contaminated blood or blood products (before 1992), as well as use or reuse of contaminated medical devices (e.g. in haemodialysis or for other purposes, such as tattooing devices, acupuncture needles, razors, and manicure devices) $[15,48]$. However, it is estimated that in Poland people who have undergone non-medical invasive procedures, such as tattoos or small esthetic treatment, are still at great risk of HCV infection[16, 19].

In different studies in various countries, the prevalence of anti-HCV positivity among healthcare workers fluctuated from $0 \%-9.7 \%$ [49]. The current study has shown rates of anti-HCV slightly lower in occupational exposures $(0.83 \%)$ than the rates estimated to occur in the general population (1\%), but similar to those seen in other studies $[50,51]$. According to a study conducted by experts from the University of Antwerp in Belgium, the transmission of $\mathrm{HCV}$ infection may vary depending on the HCV load of the source (HCV RNA positive patient), and may occur among almost $10 \%$ of the healthcare workers after parenteral exposure to blood [52]. To achieve the goal of elimination of the public health problem of this disease in healthcare sites across Europe, it is necessary to increase testing rates and the number of new diagnoses [53].

The introduction of highly effective direct-acting antivirals have changed the perspective of HCV treatment, but the major problem in Poland is the lack of a national screening programme searching for potential candidates for therapy. The presented study identified the populations with the highest antibody prevalence rate, and therefore should be considered as an optimal target group for improvement in the national strategy for $\mathrm{HCV}$ infection in Poland [54].

Some limitations to the study need to be mentioned. As this was a retrospective study, it was not possible to eliminate selection bias, as people at greater risk of $\mathrm{HCV}$ might be more likely to be referred to specialists care. Moreover, although data were collected in a standardized manner, some of the information was available only in doctors' notes. It was also not possible to retrieve information on the route of exposure for $30 \%$ of the consulted patients. Additionally, patients with anti-HCV reactive results were referred to another outpatient care department, resulting in data on HCV RNA results not being available.

\section{CONCLUSION}

Based on the results obtained, it is recommended that routine testing for HCV should be provided for people at older age and individuals with behavioural risk factors, e.g. a history of injecting drugs or sexual exposure particularly among MSM.

\section{REFERENCES}

1. Hepatitis C by the Numbers: Facts, Stats, and You (Infographic) [Available from: https://www.healthline.com/health/hepatitis-c/factsstatistics-infographic\#long--term-effects.

2. Hepatitis B and C epidemiology in selected population groups in the EU/EEA [Available from: https://www.ecdc.europa.eu/sites/default/ files/documents/Hepatitis-B-C-epidemiology-in-selected-populationsin-the-EU.pdf.

3. Chevaliez S. Strategies for the improvement of HCV testing and diagnosis. Expert review of anti-infective therapy. 2019; 17(5): 341-7.

4. Estimates of global, regional, and national incidence, prevalence, and mortality of HIV, 1980-2015: the Global Burden of Disease Study 2015. The lancet HIV. 2016; 3(8): e361-e87. 
5. Kowalska JD, Wojcik G, Rutkowski J, Ankiersztejn-Bartczak M, Siewaszewicz E. Modelling the cost-effectiveness of HIV care shows a clear benefit when transmission risk is considered in the calculations - A message for Central and Eastern Europe. PloS one. 2017; 12(11): e0186131.

6. EASL Recommendations on Treatment of Hepatitis C 2015. J Hepatol. 2015; 63(1): 199-236.

7. Aspinall EJ, Doyle JS, Corson S, Hellard ME, Hunt D, Goldberg D, et al. Targeted hepatitis $\mathrm{C}$ antibody testing interventions: a systematic review and meta-analysis. European journal of epidemiology. 2015; 30(2): 115-29.

8. Joore IK, Arts DL, Kruijer MJ, Moll van Charante EP, Geerlings SE, Prins JM, et al. HIV indicator condition-guided testing to reduce the number of undiagnosed patients and prevent late presentation in a high-prevalence area: a case-control study in primary care. Sexually transmitted infections. 2015; 91(7): 467-72.

9. Pyziak-Kowalska KA, Kowalska J, Horban A. Rationales for indicator condition-based HIV testing data from the Hospital for Infectious Diseases in Warsaw - one-year observation. HIV \& AIDS Review International Journal of HIV-Related Problems. 2017; 16(3): 191-4.

10. Raciborski F, Gujski M, Kłak A, Gierczyński J. HCV in Poland - strategy to solve the health problem and actions in perspective 2015-2016. 2015 [Available from: https://www.researchgate.net/publication/298069152.

11. NIPH-NIH. Epidemiological Reports 2018 [Available from: http:// wwwold.pzh.gov.pl/oldpage/epimeld/hiv_aids/index.htm.

12. NIPH-NIH. Infectious diseases and poisonings in Poland in 2018 [Available from: http://wwwold.pzh.gov.pl/oldpage/epimeld/2018/ INF_18_12B.pdf.

13. Flisiak R, Halota W, Tomasiewicz K, Kostrzewska K, Razavi HA, Gower EE. Forecasting the disease burden of chronic hepatitis C virus in Poland. European journal of gastroenterology \& hepatology. 2015; 27(1): 70-6.

14. Ganczak M, Korzen M, Szych Z. Seroprevalence of hepatitis C virus infection among surgical nurses, their patients and blood donation candidates in Poland. The Journal of hospital infection. 2012; 82(4): 266-70.

15. Flisiak R, Halota W, Horban A, Juszczyk J, Pawlowska M, Simon K. Prevalence and risk factors of HCV infection in Poland. European journal of gastroenterology \& hepatology. 2011; 23(12): 1213-7.

16. Rosińska M, Parda N, Kołakowska A, Godzik P, Zakrzewska K, Madaliński K, et al. Factors associated with hepatitis $\mathrm{C}$ prevalence differ by the stage of liver fibrosis: A cross-sectional study in the general population in Poland, 2012-2016. PloS one. 2017; 12(9): e0185055-e.

17. Grzeszczuk A, Wandalowicz AD, Jaroszewicz J, Flisiak R. Prevalence and Risk Factors of HCV/HIV Co-Infection and HCV Genotype Distribution in North-Eastern Poland. Hepat Mon. 2015; 15(7): e27740-e.

18. Czerwinski J, Malanowski P, Wasiak D, Pszenny A, Gutowska D, Kwiatkowski A, et al. Viral hepatitis B and C markers in the population of deceased donors in Poland. Transplantation proceedings. 2007; 39(9): 2695-7.

19. Czerwinski M, Grabarczyk P, Stepien M, Kubicka-Russel D, Tkaczuk $\mathrm{K}$, Brojer E, et al. What weighs more-low compliance with self-deferral or minor medical procedures? Explaining the high rate of hepatitis $\mathrm{C}$ virus window-period donations in Poland. Transfusion. 2017; 57(8): 1998-2006.

20. Gore C, Hicks J, Deelder W. Funding the elimination of viral hepatitis: donors needed. The lancet Gastroenterology \& hepatology. 2017; 2(12): 843-5.

21. Brouard C, Le Strat Y, Larsen C, Jauffret-Roustide M, Lot F, Pillonel J. The undiagnosed chronically-infected HCV population in France. Implications for expanded testing recommendations in 2014. PloS one. 2015; 10(5): e0126920.

22. Guardigni V, Morieri ML, Segala D, Sighinolfi L. Disease Progression in HIV Late Presenters: the Role of HIV Clinical Indicator Diseases Prior to HIV Diagnosis. Current HIV research. 2016; 14(4): 346-53.

23. Flisiak R, Frankova S, Grgurevic I, Hunyady B, Jarcuska P, Kupčinskas $\mathrm{L}$, et al. How close are we to hepatitis $\mathrm{C}$ virus elimination in Central Europe? Clinical and Experimental Hepatology. 2020; 6(1): 1-8.

24. Society PA. Recommendations 2019 [Available from: http://www. ptnaids.pl/index.php?option $=$ com_content $\&$ view $=$ article\&id $=20 \% 3$ Arekomendacje-polskiego-towarzystwa-naukowego-aids\&catid=14 $\% 3$ Arekomendacje\&Itemid $=24 \&$ lang=en.

25. Organization WH. Global Hepatitis Report 2017 [04.09.2019.]. Available from: http://apps.who.int/iris/bitstream/hand le/10665/255016/9789241565455-eng.pdf;jsessionid=A1E5CF10018D 99C7C1291A9BCA6F05A9? sequence $=1$.
26. Addiction EMCfDaD. Rapid comunication: Drug-related infectious disease in Europe: update from the EMCDDA expert network Lisbon: EMCDDA; 2017 [Available from: http://www.emcdda.europa.eu/rapidcommunications/2017/drug-related-infectious-diseases-in-europe_en.

27. Control ECfDPa. Systematic review on hepatitis $B$ and $C$ prevalence $i$ the EU/EEA Stocholm: ECDC; 2016 [Available from: https://ecdc.europa. $\mathrm{eu} /$ sites/portal/files/media/en/publications/Publications/systematicreview-hepatitis-B-C-prevalence.pdf.

28. Rosińska M, Sierosławski J, Wiessing L. High regional variability of $\mathrm{HIV}, \mathrm{HCV}$ and injecting risks among people who inject drugs in Poland: comparing a cross-sectional bio-behavioural study with case-based surveillance. BMC infectious diseases. 2015; 15: 83.

29. Wysocki MJ, Zieliński A, Gierczyński R (ed.). NIZP-PZH Warsaw 2016. p. 61-72 [Available from: http://www.jestemswiadom.org/publikacjapodsumowujaca-dzialania-i-osiagniecia-projektu-kik35-zapobieganiezakazeniom-hcv/.

30. Sierosławski J, Dąbrowska K. Zapobieganie HCV wśród użytkowników narkotyków. In: Projekt KIK/35. Zapobieganie zakażeniom HCV jako przykład zintegrowanych działań w zdrowiu publicznym na rzecz ograniczenia zakażeń krwiopochodnych w Polsce..

31. Waheed Y. Transition from millennium development goals to sustainable development goals and hepatitis. Pathogens and global health. 2015; 109(8): 353.

32. Rafik MM, El Shazly Y, Abbas AA, Abd Elhady W, Ragab D, AlShennawy D. Sexual Transmission of HCV in Heterologous Monogamous Spouses. Journal of sexually transmitted diseases. 2014; 2014: 140640.

33. Tohme RA, Holmberg SD. Is sexual contact a major mode of hepatitis C virus transmission? Hepatology (Baltimore, Md). 2010; 52(4): 1497-505.

34. Grady BP, Prins M, van der Loeff MS. The sexual transmission rate of HCV among heterosexual couples. Hepatology (Baltimore, Md). 2013; 58(5): 1865-6.

35. Duffell EF, Hedrich D, Mardh O, Mozalevskis A. Towards elimination of hepatitis B and C in European Union and European Economic Area countries: monitoring the World Health Organization's global health sector strategy core indicators and scaling up key interventions. Eurosurveillance. 2017; 22(9).

36. Cainelli F. Hepatitis $\mathrm{C}$ virus and human immunodeficiency virus transmission routes: Differences and similarities. World journal of hepatology. 2013; 5(5): 234-6.

37. Kouyos RD, Rauch A, Boni J, Yerly S, Shah C, Aubert V, et al. Clustering of HCV coinfections on HIV phylogeny indicates domestic and sexual transmission of HCV. International journal of epidemiology. 2014; 43(3): 887-96.

38. Chan DPC, Sun H-Y, Wong HTH, Lee S-S, Hung C-C. Sexually acquired hepatitis $\mathrm{C}$ virus infection: a review. International Journal of Infectious Diseases. 2016; 49: 47-58.

39. Vaux S, Chevaliez S, Saboni L, Sauvage C, Sommen C, Barin F, et al. Prevalence of hepatitis $\mathrm{C}$ infection, screening and associated factors among men who have sex with men attending gay venues: a crosssectional survey (PREVAGAY), France, 2015. BMC infectious diseases. $2019 ; 19(1): 315$.

40. Nijmeijer BM, Koopsen J, Schinkel J, Prins M, Geijtenbeek TB. Sexually transmitted hepatitis $\mathrm{C}$ virus infections: current trends, and recent advances in understanding the spread in men who have sex with men. Journal of the International AIDS Society. 2019; 22(S6): e25348.

41. Parczewski M, Cielniak I, Kordek J, Aksak-Wąs B, Urbańska A, Leszczyszyn-Pynka M, et al. Transmission Networks of HCV Genotype 1a Enriched With Pre-existing Polymorphism Q80K Among HIVInfected Patients With Acute Hepatitis C in Poland. Journal of acquired immune deficiency syndromes. 2018; 77(5): 514-22.

42. Transmission Networks of HCV Genotype 1a Enriched With Preexisting Polymorphism Q80K Among HIV-Infected Patients With Acute Hepatitis C in Poland: Erratum. Journal of acquired immune deficiency syndromes. 2019; 81(1): e27.

43. Committee on a National Strategy for the Elimination of Hepatitis B, Board on Population H, Public Health P, Health, Medicine D, National Academies of Sciences E, et al. In: Buckley GJ, Strom BL, editors. Eliminating the Public Health Problem of Hepatitis B and C in the United States: Phase One Report. Washington (DC): National Academies Press (US). Copyright 2016 by the National Academy of Sciences. All rights reserved.; 2016.

44. Grebely J, Bilodeau M, Feld JJ, Bruneau J, Fischer B, Raven JF, et al. The Second Canadian Symposium on hepatitis C virus: a call to action. Canadian journal of gastroenterology=Journal canadien de gastroenterologie. 2013; 27(11): 627-32.

45. Neukam K, Ridruejo E, Perez P, Campos RH, Martinez AP, Di Lello FA. Prevalence of hepatitis $\mathrm{C}$ virus infection according to the year of birth: 
identification of risk groups. European journal of clinical microbiology $\&$ infectious diseases: official publication of the European Society of Clinical Microbiology. 2018; 37(2): 247-54.

46. Walewska-Zielecka B, Religioni U, Juszczyk G, Wawrzyniak ZM, Czerw A, Soszyński $\mathrm{P}$, et al. Anti-hepatitis $\mathrm{C}$ virus seroprevalence in the working age population in Poland, 2004 to 2014. Eurosurveillance. 2017; 22(2).

47. Hartleb M, Gutkowski K, Zejda JE, Chudek J, Wiecek A. Serological prevalence of hepatitis $B$ virus and hepatitis $C$ virus infection in the elderly population: Polish nationwide survey--PolSenior. European journal of gastroenterology \& hepatology. 2012; 24(11): 1288-95.

48. Sakem B, Madaliński K, Nydegger U, Stępień M, Godzik P, Kołakowska A, et al. Hepatitis $C$ virus epidemiology and prevention in Polish and Swiss population - similar and contrasting experiences. Annals of Agricultural and Environmental Medicine. 2016; 23(3): 425-31.

49. Coppola N, De Pascalis S, Onorato L, Calo F, Sagnelli C, Sagnelli E. Hepatitis $B$ virus and hepatitis $C$ virus infection in healthcare workers. World journal of hepatology. 2016; 8(5): 273-81.
50. Slusarczyk J, Malkowski P, Bobilewicz D, Juszczyk G. Cross-sectional, anonymous screening for asymptomatic $\mathrm{HCV}$ infection, immunity to $\mathrm{HBV}$, and occult HBV infection among health care workers in Warsaw, Poland. Przeglad epidemiologiczny. 2012; 66(3): 445-51.

51. Rybacki M, Piekarska A, Wiszniewska M, Walusiak-Skorupa J. Hepatitis $B$ and Cinfection: is it a problem in Polish healthcare workers? International journal of occupational medicine and environmental health. 2013; 26(3): 430-9.

52. Elseviers MM, Arias-Guillen M, Gorke A, Arens HJ. Sharps injuries amongst healthcare workers: review of incidence, transmissions and costs. Journal of renal care. 2014; 40(3): 150-6.

53. Fourati S, Feld JJ, Chevaliez S, Luhmann N. Approaches for simplified HCV diagnostic algorithms. Journal of the International AIDS Society. 2018; 21 Suppl 2: e25058.

54. Piekarska A, Tomasiewicz K, Halota W, Jaroszewicz J, Krygier R, Małkowski P, et al. Searching for the optimal population for hepatitis $\mathrm{C}$ virus screening in Poland. Clinical and Experimental Hepatology. 2020; 6(2): 74-6. 